\title{
Improvement of Sodium Leaching Ratio of Ferric Bauxite Sinter after Direct Reduction
}

\author{
Wentao Hu ${ }^{1,2}$, Xinwei Liu ${ }^{3}$, Huajun Wang ${ }^{1,2, *}$, Xiaojie Dai ${ }^{1}$, Dongling Pan ${ }^{1}$, Jia Li ${ }^{1}$, \\ Chuanyao Sun ${ }^{1,2}$, Hanwen Xia ${ }^{1}$ and Bo Wang ${ }^{1}$ \\ 1 State Key Laboratory of High-Efficient Mining and Safety of Metal Mines (USTB), Ministry of Education, \\ Beijing Key Laboratory of Resource-Oriented Treatment of Industrial Pollutants, University of Science and \\ Technology Beijing, Beijing 100083, China; huwentao010@gmail.com (W.H.); 41414037@xs.ustb.edu.cn (X.D.); \\ 41414057@xs.ustb.edu.cn (D.P.); 41414041@xs.ustb.edu.cn (J.L.); sunchy@cae.cn (C.S.); \\ xiaxiax123@gmail.com (H.X.); wangboustb@gmail.com (B.W.) \\ 2 State Key Laboratory of Mineral Processing Science and Technology, Beijing General Research Institute of \\ Mining and Metallurgy, Beijing 100070, China \\ 3 Industrial Research Department, China Noferrous Metals Industry Association Recycling Metal Branch, \\ Beijing 100037, China; alabozhizi@gmail.com \\ * Correspondence: wanghuajun@bjjzq.com; Tel.: +86-10-6233-2902 \\ Academic Editor: Saeed Chehreh Chelgani \\ Received: 6 November 2016; Accepted: 21 December 2016; Published: 18 January 2017
}

\begin{abstract}
The sodium leaching ratio $\left(\eta_{N}\right)$ of ferric bauxite direct reduction process is much lower than that of ordinary bauxite; thus, the former consumes more sodium than the latter. $\eta_{N}$ can be promoted by increasing the dosage of sodium or restricted by increasing the heating temperature and time. However, the restriction effect of heating temperature is 16.67 times larger than that of heating time, and the restriction effect decreases 47.03 times faster when heating temperature increases than that process of heating time. These imply that $\eta_{N}$ improves with the increasing sodium carbonate dosage and the decreasing heating temperature.
\end{abstract}

Keywords: ferric bauxite; leaching; direct reduction; sodium

\section{Introduction}

Ferric bauxite is a typical refractory bauxite which has a wide distribution in Asia [1-3] and Africa [1], however, it is improperly developed. The potential methods of treating ferric bauxite include the extraction of alumina before iron [4,5], extraction of iron before alumina [6,7], beneficiation before leaching [8], and biological technique [9,10]. Direct reduction before leaching is another method [11-13] that has recently seen a boom. By adopting this technology, hematite and goethite in ferric bauxite are reduced to granular iron in a carbothermic reduction process, and then iron powder is separated from the sinter produced after the reduction. Iron powder may then be employed for producing steel and casting after agglomeration, or used as a metallic powder material directly. Simultaneous with hematite and goethite reduction, the additive of sodium carbonate reacted with diaspore and boehmite then generates water-soluble sodium aluminate, which is then separated from the solution obtained after leaching and utilized for alumina production. In the alumina leaching process, sodium is also leached out and recycled partially. However, before reduction, iron-containing minerals react with sodium carbonate to generate evaporable sodium ferrite, and silicon-containing minerals react with sodium carbonate to generate nepheline $[12,14]$. These reactions reduce sodium leaching ratio and increase alkali consumption. The Box-Benhken design [15] is typically adopted to conduct quantitative research by determining the regression model. In this research, Box-Benhken design is utilized to investigate the effects of heating temperature, heating time, and sodium carbonate dosage on sodium leaching ratio and to understand the change patterns of these effects. The results of this study may be 
used to reduce the alkali consumption of the direct reduction of ferric bauxite. The findings may also improve current alumina production.

\section{Experimental}

\subsection{Experimental Methods}

The experimental instruments employed in this investigation include a rod mill (Hengcheng, XMB-70, Ganzhou, China), an electric box furnace (INCH, SX $2-10-13$, Changsha, China), an electronic balance (Mettler, AR1140, Changzhou, China), a vacuum filter (Hengcheng, XTLZ, Ganzhou, China), a magnetic separator (Yihao, CXG-99, Tangshan, China), and an electrothermal constant-temperature dry box (Shuangxu, PH050, Shanghai, China).

The Chemical compositions of the ore and product were analyzed by an atomic absorption spectrophotometer (Rayleigh, UV-9600, Beijing, China). The mineral composition of ore was examined by an X-ray diffractometer, XRD (Rigaku, TTRIII, Tokyo, Japan). The morphology and chemical composition of micro zone in samples were determined using a scanning electron microscope equipped with an energy dispersive spectrometer, SEM-EDS (ZEISS, EVO 18, Jena, Germany).

The chemical and mineral compositions of ferric bauxite were examined by atomic absorption spectrophotometer and XRD, respectively. The microstructure and chemical composition were tested by SEM-EDS.

In the experiments, ore, sodium carbonate, and coal were crushed to $100 \%$ passing $2 \mathrm{~mm}$, and then mixed. The mixing ratio of ore and coal was 1:0.25, whereas the amount of sodium carbonate was varied. In each unit experiment, $41 \mathrm{~g}$ of the mixed materials was transferred to a lidded $100 \mathrm{~mL}$ graphite clay crucible. The crucible was then placed in a muffle furnace with an uncontrolled gaseous atmosphere at 1100 to $1150{ }^{\circ} \mathrm{C}$. A distance of more than $3 \mathrm{~cm}$ was left between the crucible lid and the powder mixture in the crucible to prevent them from making contact with each other. After cooling, the material was ground to $100 \%$ passing $74 \mu \mathrm{m}$ at the grinding density of $50 \%$, and then leached under the conditions of water-solid ratio of $15: 1$, leaching temperature of $75^{\circ} \mathrm{C}$, and leaching time of $0.5 \mathrm{~h}$. Sodium leaching ratio $\left(\eta_{\mathrm{N}}\right)$ was then calculated from Equation (1):

$$
\eta_{N}=\frac{46 \cdot c_{N} \cdot V_{o l}}{106 \cdot M \cdot \omega_{N}}
$$

$\eta_{N}$, sodium leaching ratio, $\%$;

$c_{N}$, sodium concentration of lixivium, $\mathrm{g} / \mathrm{L}$;

$V_{o l}$, volume of lixivium, L;

$M$, mass of raw material mixture adopted in each unit experiment, $\mathrm{g}$;

$\omega_{N}$, mass fraction of sodium carbonate in raw material mixture, $\%$.

The leaching residues were transferred to magnetic separators, and the iron powder was isolated from tailing with a magnetic separation of $0.14 \mathrm{~T}$. The entire flow chart adopted in the experiments is shown in Figure 1, but only the sodium leaching part was investigated in this study. 


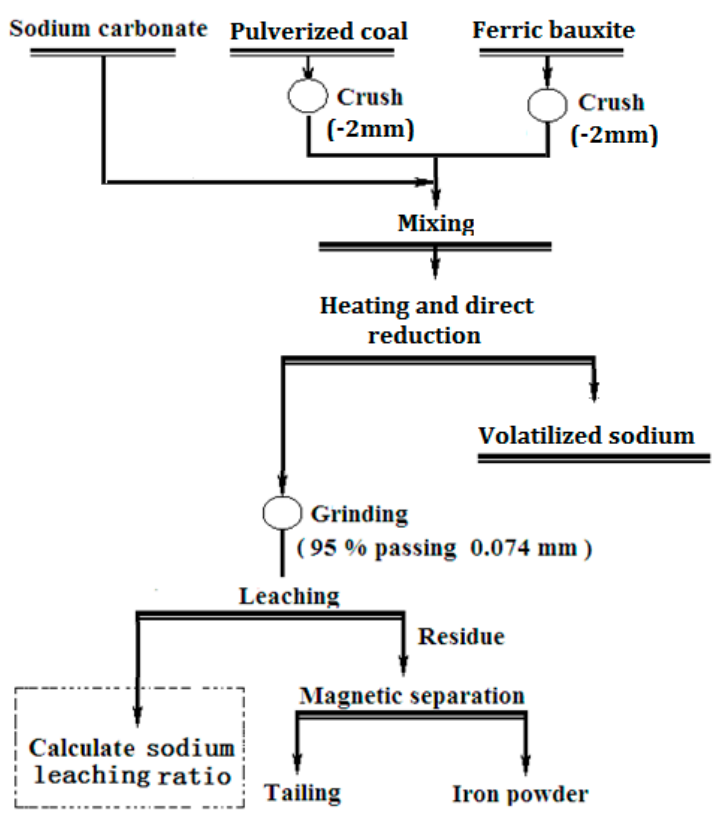

Figure 1. The entire flow chat adopted in the experiment.

\subsection{Ore Characteristics}

The ferric bauxite used was sampled from the Guangxi province of China. The chemical composition, SEM-EDS photos, and XRD image of the ferric bauxite adopted are presented in Table 1 and Figures 2 and 3, respectively.

Table 1. The chemical composition of the ferric bauxite adopted.

\begin{tabular}{ccccccccccc}
\hline Compositions & $\mathrm{Fe}_{2} \mathbf{O}_{3}$ & $\mathrm{Al}_{2} \mathbf{O}_{3}$ & $\mathbf{S i O}_{2}$ & $\mathrm{TiO}_{2}$ & $\mathbf{M g O}$ & $\mathbf{C a O}$ & $\mathbf{N a}_{2} \mathbf{O}$ & $\mathbf{K}_{\mathbf{2}} \mathbf{O}$ & $\mathbf{P}_{2} \mathbf{O}_{5}$ & LOI \\
\hline Content $/ \%$ & 41.13 & 33.02 & 12.22 & 1.49 & 0.68 & 0.63 & 0.32 & 0.06 & 0.04 & 8.97 \\
\hline
\end{tabular}

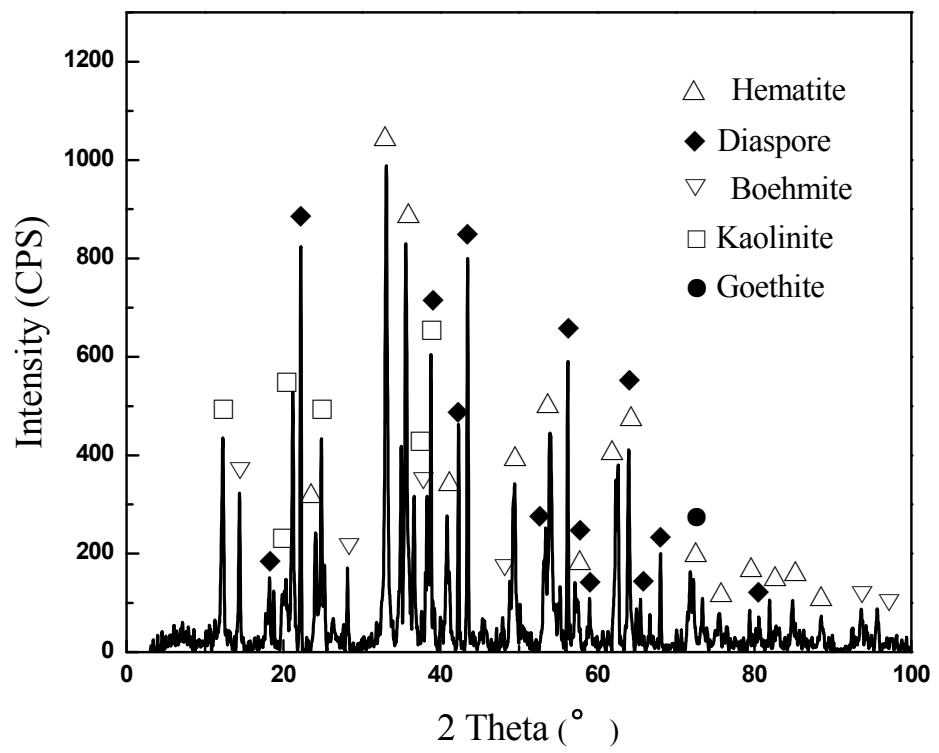

Figure 2. The XRD image of the ferric bauxite adopted.

Table 1 indicates that the iron and silicon dioxide of ferric bauxite are $28.79 \%$ and $12.22 \%$, respectively. Figure 2 shows five main crystalline mineral phases in raw ferric bauxite: hematite, 
boehmite, diaspore, kaolinite, and goethite. Figure 3 reveals that the minerals in ferric bauxite are finely disseminated and symbiotic with one another, particularly the fine disseminated silicon-containing minerals distributed in hematite and diaspore grains (see points 5 and 6 in Figure 3a). Ferric bauxite is characterized by the high contents of iron and silicon dioxide, as well as finely disseminated and symbiotic silicon-containing mineral.

Proximate analysis and inorganic composition data of coal are shown in Tables 2 and 3, respectively.

Table 2. Proximate analysis of the coal used.

\begin{tabular}{ccccc}
\hline Compositions & Total Moisture $\left(\mathbf{M}_{\mathbf{t}}\right)$ & Volatiles $\left(\mathrm{V}_{\mathrm{ad}}\right)$ & Ash $\left(\mathbf{A}_{\mathbf{a d}}\right)$ & Fixed Carbon $\left(\mathrm{FC}_{\mathbf{a d}}\right)$ \\
\hline Content $/ \%$ & 9.16 & 39.42 & 5.07 & 46.35 \\
\hline
\end{tabular}

Table 3. Inorganic composition of coal ash.

\begin{tabular}{lccccccccc}
\hline Component & $\mathrm{SiO}_{2}$ & $\mathrm{Al}_{2} \mathbf{O}_{3}$ & $\mathrm{Fe}_{\mathbf{2}} \mathbf{O}_{3}$ & $\mathbf{M g O}$ & $\mathrm{CaO}$ & $\mathrm{Na}_{\mathbf{2}} \mathbf{O}$ & $\mathbf{K}_{\mathbf{2}} \mathbf{O}$ & $\mathrm{TiO}_{2}$ & $\mathbf{P}_{\mathbf{2}} \mathbf{O}_{5}$ \\
\hline Content $/ \%$ & 38.0 & 21.37 & 36.19 & 1.9 & 7.15 & 0.43 & 1.38 & 0.84 & 0.41 \\
\hline
\end{tabular}

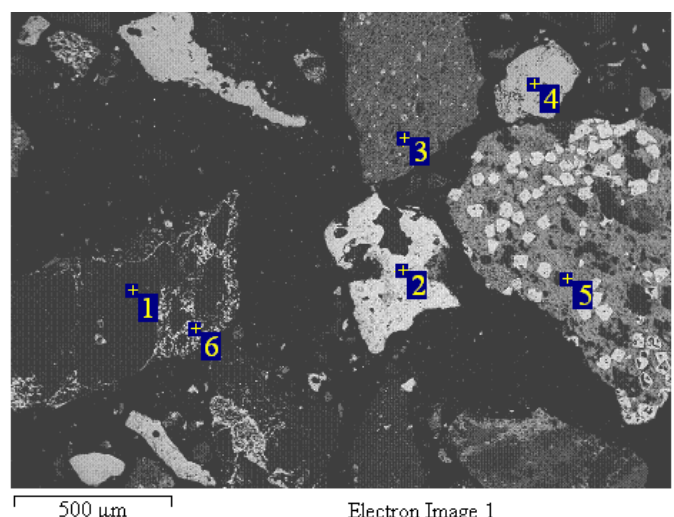

(a)

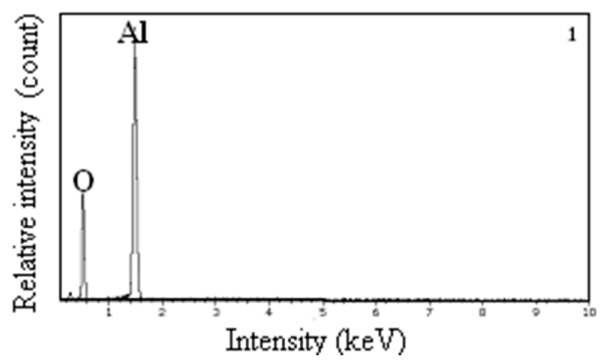

(b)

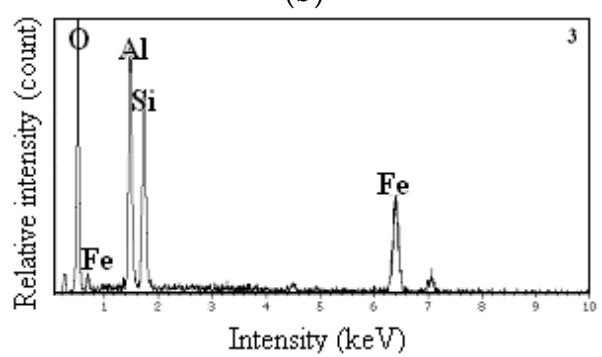

(d)

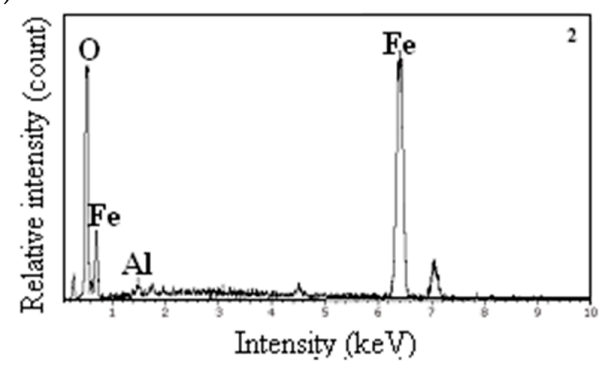

(c)

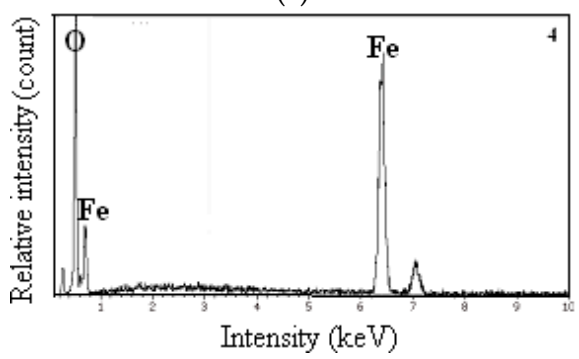

(e)

Figure 3. Cont. 


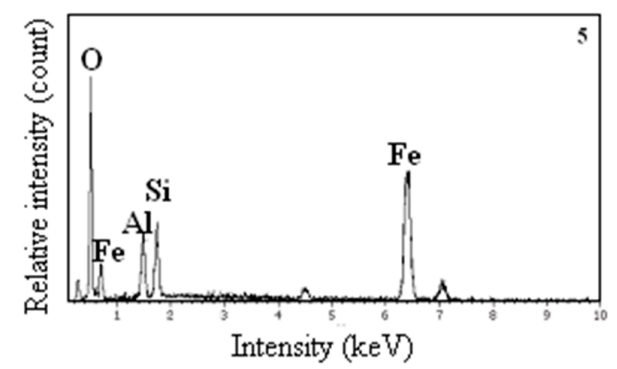

$(\mathrm{f})$

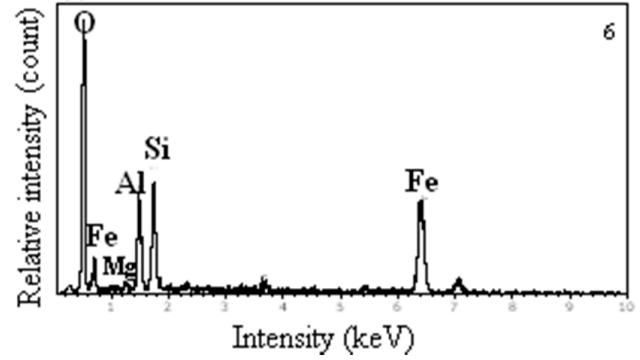

(g)

Figure 3. (a) The SEM image of the ferric bauxite adopted; (b) energy dispersive spectrometer image of point 1 ; (c) the EDS image of point 2; (d) the EDS image of point 3; (e) the EDS image of point 4 ; (f) the EDS image of point $5 ;(\mathrm{g})$ the EDS image of point 6.

\section{Results and Discussion}

\subsection{Leaching Rules}

Coal dosage, heating temperature, heating time, and sodium carbonate dosage are the four significant factors that influence ferric bauxite direct reduction and leaching process [14]. Among them, coal dosage is usually determined by the hematite content of ore, and can hardly be changed to promote $\eta_{N}$. Thus, only the effects of heating temperature, heating time, and sodium carbonate dosage on $\eta_{N}$ were measured in this research, and every experiment was conducted under a constant coal dosage. The parameter scales were established under previously reported optimum conditions [16], because $\eta_{N}$ must be promoted on the premise of synthetically recovering iron and aluminum. In the Box-Benhken design, the fluctuation range of each parameter scale is $10 \%$. The Box-Benhken design and experiment results are shown in Table 4.

Table 4. Box-Benhken design and experiment results.

\begin{tabular}{ccccc}
\hline \multirow{2}{*}{ No. } & \multicolumn{3}{c}{ Experimental Factors } & \multirow{2}{*}{$\eta_{N}(\%)$} \\
\cline { 2 - 4 } & Heating Temperature $\left({ }^{\circ} \mathbf{C}\right)$ & Heating Time $(\mathbf{m i n})$ & Sodium Carbonate Dosage (\%) & \\
\hline 1 & 1035 & 49.5 & 85 & 66.05 \\
2 & 1035 & 40.5 & 85 & 67.04 \\
3 & 1035 & 45 & 93.5 & 66.49 \\
4 & 1035 & 45 & 76.5 & 67.56 \\
5 & 1150 & 49.5 & 76.5 & 63.75 \\
6 & 1150 & 49.5 & 93.5 & 60.68 \\
7 & 1150 & 40.5 & 76.5 & 64.04 \\
8 & 1150 & 45 & 93.5 & 59.70 \\
9 & 1150 & 45 & 85 & 59.31 \\
10 & 1150 & 45 & 85 & 59.55 \\
11 & 1150 & 45 & 85 & 59.12 \\
12 & 1150 & 45 & 85 & 59.47 \\
13 & 1150 & 45 & 85 & 51.81 \\
14 & 1265 & 40.5 & 76.5 & 51.52 \\
15 & 1265 & 49.5 & 93.5 & 46.63 \\
16 & 1265 & & 85 & 45.30 \\
\hline
\end{tabular}

Research shows the appropriate model simulated by Box-Behnken is quadratic. The variance analysis of the regression models is shown in Table 5 , where $D_{f}$ is the degrees of freedom (a non-dimensional number), $F$ is the homogeneity test of variance, $P$ is the probability of obtaining a result that is at least as extreme as the actually observed result, given that the null hypothesis is true.

Using a quadratic model, it was calculated that $\mathrm{R}^{2}=740.12 / 758.72=0.9755$. This indicates that $97.55 \%$ of the $\eta_{N}$ changes coming from the factors have been considered. The lack of fit value and the significance level of the model selected show that the model and experimental data fit well, using quadratic to describe the quantitative relation between $\eta_{N}$ and its influence factors is appreciated. 
Table 5. Variance analysis of regression models.

\begin{tabular}{ccccccc}
\hline Source & Sum of Squares & $\boldsymbol{D}_{f}$ & Mean Squares & $\boldsymbol{F}$ & $\boldsymbol{P}$-Value Prob $\boldsymbol{P}$ & Result \\
\hline Model & 740.12 & 9 & 82.24 & 30.95 & $<0.0001$ & Significant \\
A & 663.85 & 1 & 663.85 & 249.85 & $<0.0001$ & Significant \\
B & 0.03 & 1 & 0.03 & 0.13 & 0.7736 & - \\
C & 7.54 & 1 & 7.54 & 2.84 & 0.1359 & - \\
AB & 0.028 & 1 & 0.028 & 0.01 & 0.9213 & - \\
AC & 0.79 & 1 & 0.79 & 0.3 & 0.6033 & - \\
BC & 0.41 & 1 & 0.41 & 0.15 & 0.7077 & - \\
A $^{2}$ & 38.27 & 1 & 38.27 & 14.4 & 0.0068 & - \\
$B^{2}$ & 0.017 & 1 & 0.017 & $6.4378 \times 10^{-3}$ & 0.9383 & - \\
C $^{2}$ & 32.41 & 1 & 32.41 & 12.2 & 0.01 & - \\
Residual & 18.6 & 7 & 2.66 & - & - & - \\
Lack of Fit & 18.48 & 3 & 6.16 & 203.26 & $<0.0001$ & - \\
Pure Error & 0.12 & 4 & 0.03 & - & - & - \\
Cor Total & 758.72 & 16 & - & - & &
\end{tabular}

The confidence analysis of the quadratic model is shown in Table 6, where $D_{f}$ is the degrees of freedom (a non-dimensional number), and VIF is the variance inflation factor (a non-dimensional number).

Table 6. Confidence analysis of the quadratic model. VIF: variance inflation factor.

\begin{tabular}{ccccccc}
\hline Factor & Coefficient Estimate & $\boldsymbol{D}_{f}$ & Standard Error & $\mathbf{9 5 \%}$ Cl Low & $\mathbf{9 5 \%}$ Cl High & VIF \\
\hline Intercept & 59.33 & 1 & 0.73 & 57.61 & 61.06 & - \\
A-Temperature & -9.11 & 1 & 0.58 & -10.47 & -7.75 & 1.00 \\
B-Time & -0.2 & 1 & 0.58 & -1.57 & 1.16 & 1.00 \\
C-sodium carbonate & -0.97 & 1 & 0.58 & -2.33 & 0.39 & 1.00 \\
AB & -0.083 & 1 & 0.82 & -2.01 & 1.84 & 1.00 \\
AC & 0.44 & 1 & 0.82 & -1.48 & 2.37 & 1.00 \\
BC & 0.32 & 1 & 0.82 & -1.61 & 2.25 & 1.00 \\
$\mathrm{~A}^{2}$ & -0.31 & 1 & 0.79 & -4.89 & -1.14 & 1.01 \\
$\mathrm{~B}^{2}$ & -0.064 & 1 & 0.79 & -1.94 & 1.81 & 1.01 \\
$\mathrm{C}^{2}$ & 0.27 & 1 & 0.79 & 0.9 & 4.65 & 1.01 \\
\hline
\end{tabular}

The variance analysis of the regression models in Table 5 shows that the quadratic model fits the data well. The response surfaces of the heating temperature-heating time plot and their corresponding contours are shown in Figure 4. The response surfaces of the heating time-sodium carbonate dosage plot and their corresponding contours are shown in Figure 5. The response surfaces of the heating temperature-sodium carbonate dosage plot and their corresponding contours are shown in Figure 6.

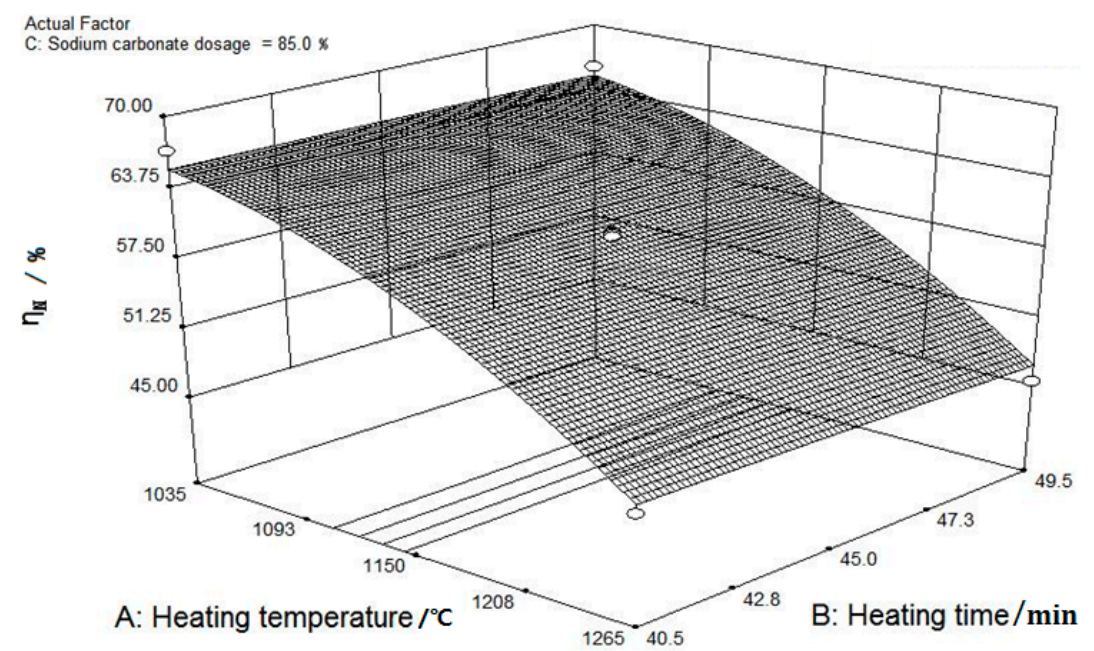

(a)

Figure 4. Cont. 


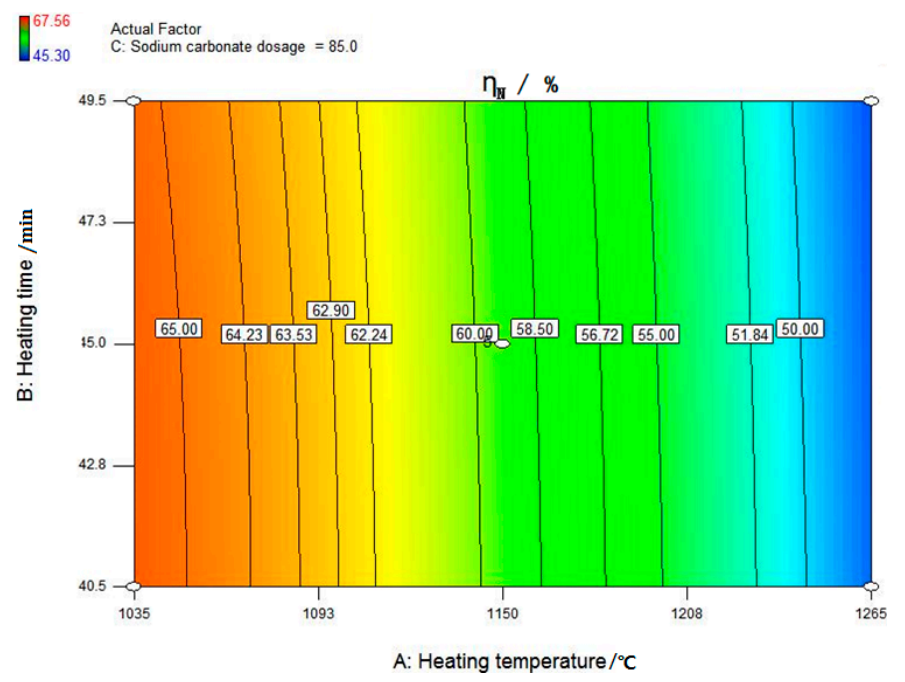

(b)

Figure 4. (a) Response surface of heating temperature-heating time plot; (b) contour of heating temperature-heating time plot.

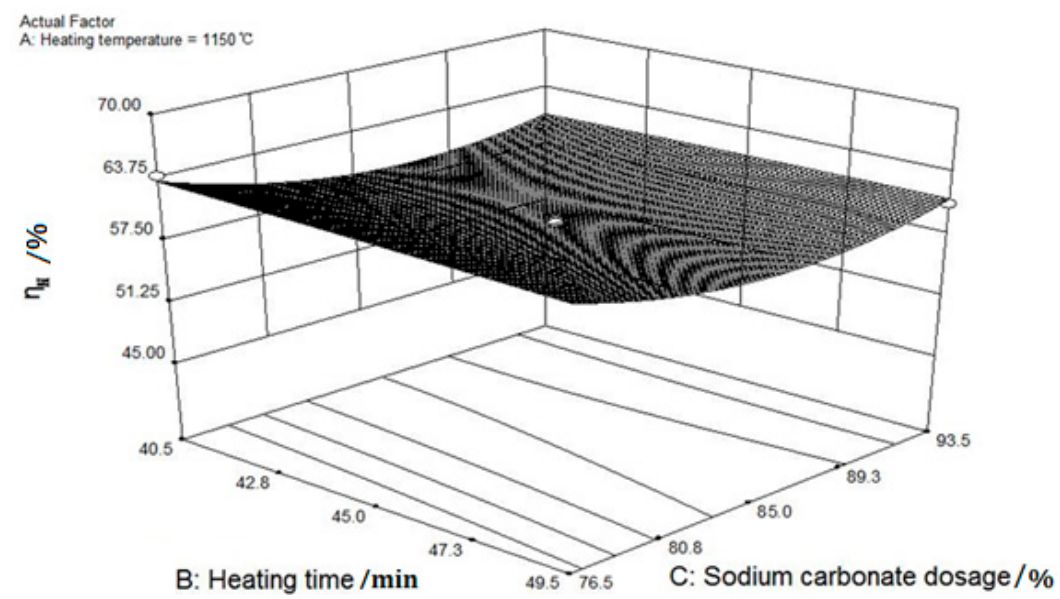

(a)

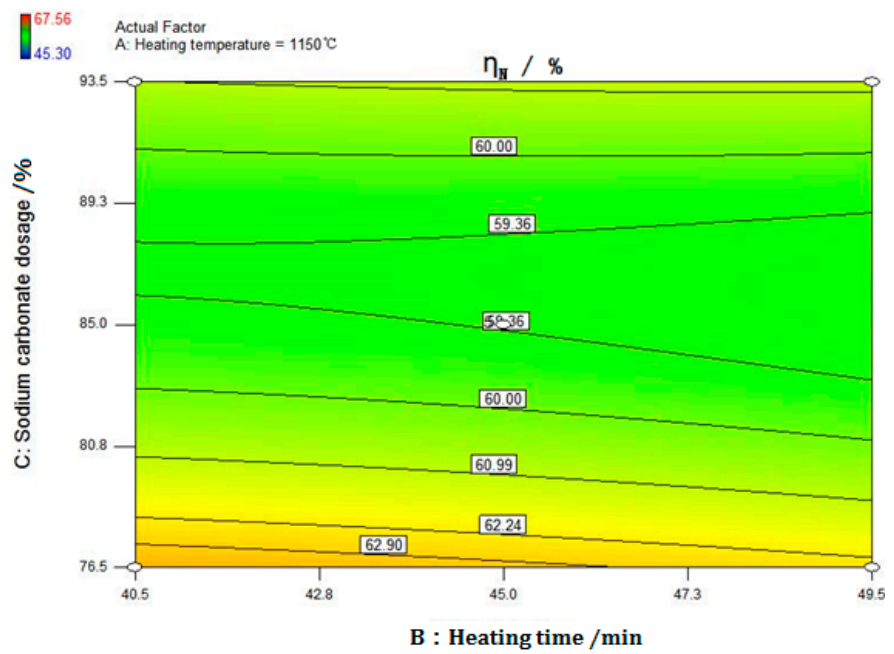

(b)

Figure 5. (a) Response surface of heating time-sodium carbonate dosage; (b) contour of heating time-sodium carbonate dosage plot. 


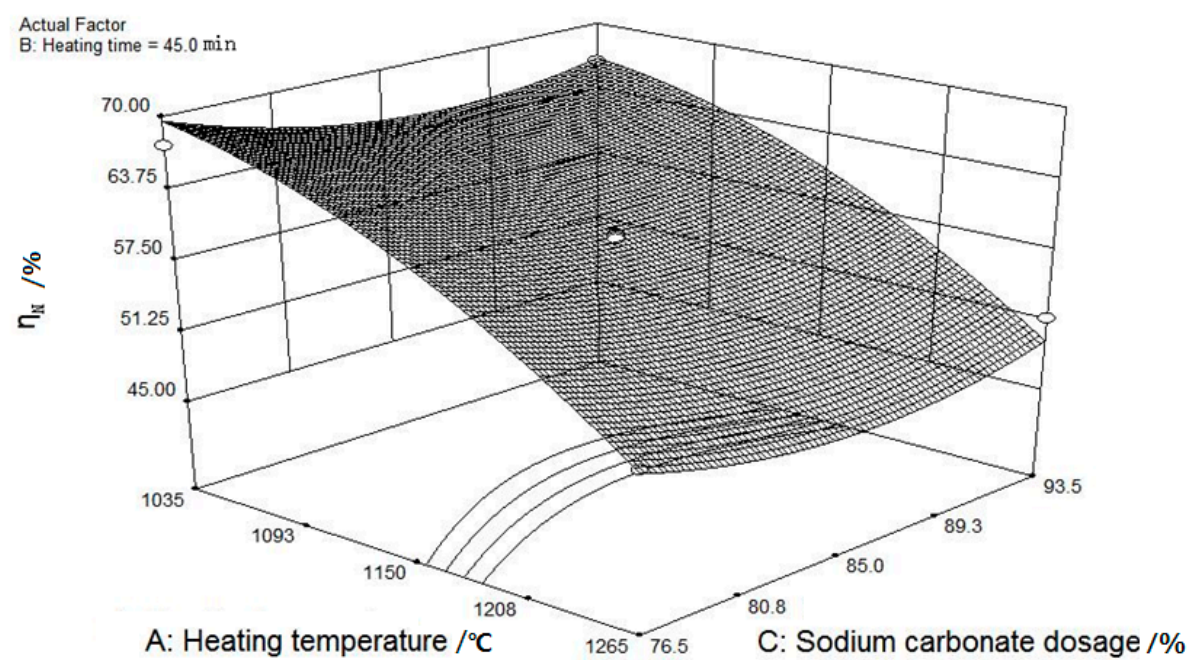

(a)

Actual Factor
B. Heating time $=45.0 \mathrm{~min}$

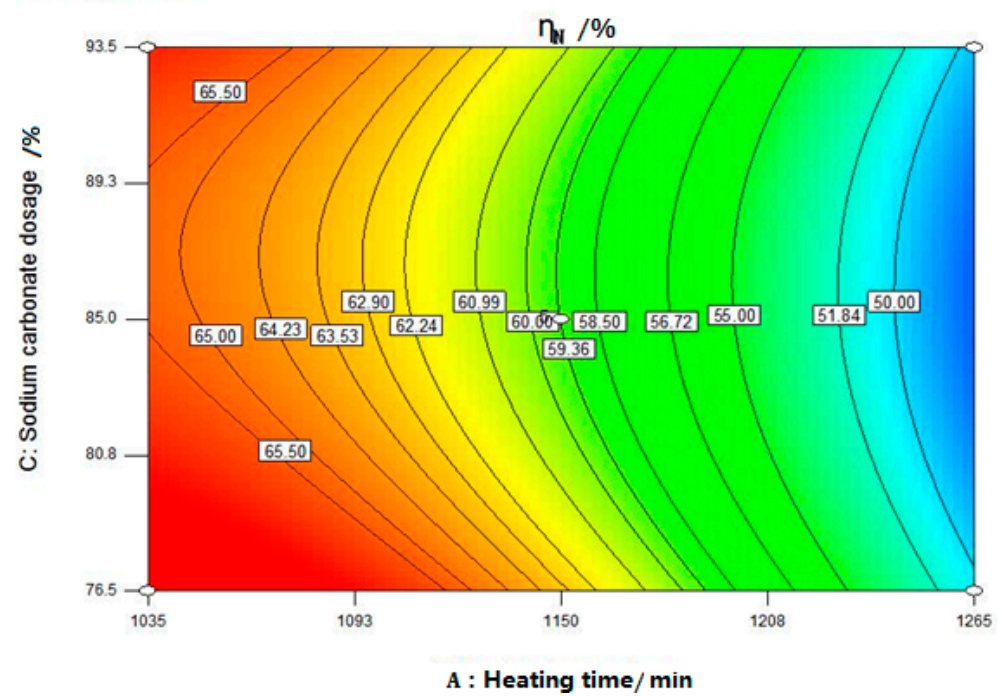

(b)

Figure 6. (a) Response surface of heating temperature-sodium carbonate dosage; (b) contour of heating temperature-sodium carbonate dosage plot.

Figures 4-6 show that the value gradients correlated with heating temperature is much sharper than that with sodium carbonate dosage and heating time. Exerting the minimal impact on $\eta_{N}$, the effect of heating time is negligible. Namely, the significance of the influencing factors of $\eta_{N}$ can be arranged in descending order, as follows: heating temperature > sodium carbonate dosage > heating time.

\subsection{Quantitative Analysis of Leaching Model}

The quadratic model suggested by Box-Behnken design is shown in Equation (2).

$$
\eta_{N}=-3.01 A^{2}-0.064 B^{2}+2.77 C^{2}-0.083 A B+0.44 A C+0.32 B C-9.11 A-0.2 B-0.97 C+59.33
$$

Generally, the changing rate and speed of a quantity can be described by calculating its partial derivative and second partial derivative. Specifically, the effects of heating temperature $(A)$, heating time $(B)$, and sodium carbonate dosage $(C)$ on $\eta_{N}$ changings mean promotion or restraint; thus, these promotion or restraint effects can be investigated by calculating the partial derivative and 
second partial derivative of $\eta_{N}$. Necessary processes and the results of the calculation are shown in Equations (3)-(8).

$$
\begin{aligned}
& \frac{\partial \eta_{N}}{\partial A} \mid \begin{array}{l}
A=1150 \\
B=2700 \\
C=40.75
\end{array}=-6.02 A-0.083 B+0.44 C-9.11=-7138.2 \\
& \frac{\partial^{2} \eta_{N}}{\partial A^{2}}=6.02 \\
& \frac{\partial \eta_{N}}{\partial B} \mid \begin{array}{l}
A=1150 \\
B=2700 \\
C=40.75
\end{array}=-0.128 B-0.083 A+0.32 C-0.2=-428.21 \\
& \frac{\partial^{2} \eta_{N}}{\partial B^{2}}=-0.128 \\
& \begin{array}{l|l}
\partial \eta_{N} & \begin{array}{l}
A=1150 \\
B C
\end{array} \mid \begin{array}{l}
B=2700=5054 C+0.44 A-0.97=1590.71 \\
C=40.75
\end{array}
\end{array} \\
& \frac{\partial^{2} \eta_{N}}{\partial C^{2}}=5.54
\end{aligned}
$$

Analysis shows that $\frac{\partial \eta_{N}}{\partial A}<\frac{\partial \eta_{N}}{\partial B}<0$ when $A=1150^{\circ} \mathrm{C}, B=45 \mathrm{~min}$, and $C=40.75 \%$, indicating that $\eta_{N}$ is restricted with increasing heating temperature and heating time. In addition, the restriction effect of the former is 16.67 times larger than that of the latter. $\frac{\partial \eta_{N}}{\partial C}>0$ means that $\eta_{N}$ increases with increasing sodium carbonate dosage. $\frac{\partial^{2} \eta_{N}}{\partial A^{2}}=-6.02<\frac{\partial^{2} \eta_{N}}{\partial B^{2}}=-0.128<0$ indicates that the restriction effects of heating temperature and time on $\eta_{N}$ decrease, and the decrease of the former is 47.03 times larger than that of the latter. $\frac{\partial^{2} \eta_{N}}{\partial C^{2}}=5.54>0$ indicates that the promoting effect from the increase in sodium carbonate dosage will become reinforced. Therefore, sodium leaching improves with increasing sodium carbonate dosage and decreasing heating temperature. However, taking economic effects into consideration, the increasing of sodium carbonate dosage means more materials costs, while the decreasing of heating temperature reduces fuel consumption. Thus, in addition to the technical factor, it is also necessary to perform a financial evaluation to verify the economic value of these optimality conditions.

\section{Conclusions}

Ferric bauxite is characterized by high contents of iron and silicon dioxide, as well as finely disseminated and symbiotic silicon-containing mineral. $\eta_{N}$ can be promoted by increasing sodium carbonate dosage. The promotion effect can be restricted by increasing the heating temperature and time. The restriction effect of heating temperature is 16.67 times larger than that of heating time. However, the decreasing effects of heating temperature and time on $\eta_{N}$ both reduce when heating temperature or heating time increase, but the effect of heating temperature weakens 47.03 times faster than that of heating time. Therefore, in conclusion, sodium leaching improves with increasing sodium carbonate dosage and decreasing heating temperature.

Acknowledgments: This study was supported by the National Natural Science Foundation of China by a grant number 51304012, the Found of State Key Laboratory of Mineral Processing by a grant number BGRIMM-KJSKL-2015-08, the State Key Laboratory of Solid Waste Reuse for Building Materials by a grant number of SWR-2015-003, the Fundamental Research Funds for the Central Universities by a grant number FRF-TP-15-050A1, and the Open Foundation of the State Key Laboratory of Advanced Metallurgy (USTB) by a grant number KF 13-04 and 13-05. 
Author Contributions: Wentao $\mathrm{Hu}$ and Chuanyao Sun conceived the experiments; Wentao Hu, Xinwei Liu, Hanwen Xia, and Bo Wang performed the experiments; Huajun Wang contributed experimental materials and analysis tools; Wentao $\mathrm{Hu}$ wrote the paper; Wentao $\mathrm{Hu}$, Xiaojie Dai, Dongling Pan, and Jia Li made the final modification.

Conflicts of Interest: The authors declare no conflict of interest.

\section{References}

1. Cheng, G.; Gao, G.M.; Chen, S.L. Geological characteristics and mineralization regularity of bauxite in Boloven Plateau Laos. J. Cent. South Univ. Nat. Sci. Ed. 2008, 39, 380-386.

2. Deng, J.; Wang, Q.F.; Yang, S.J.; Liu, X.F.; Zhang, Q.Z.; Yang, L.Q.; Yang, Y.H. Genetic relationship between the Emeishan plume and the bauxite deposits in Western Guangxi, China: Constraints from U-Pb and Lu-Hf isotopes of the detrital zircons in bauxite ores. J. Asian Earth Sci. 2010, 37, 412-424. [CrossRef]

3. Zhang, Z.W.; Zhou, L.J.; Li, Y.J.; Wu, C.Q.; Zheng, C.F. The "coal-bauxite-iron" structure in the ore-bearing rock series as a prospecting indicator for southeastern Guizhou bauxite mines. Ore Geol. Rev. 2013, 53, 145-158. [CrossRef]

4. Zwingmann, N.; Jone, A.J.; Dye, S.; Swash, P.M.; Gilkes, R.J. A method to concentrate boehmite in bauxite by dissolution of gibbsite and iron oxides. Hydrometallurgy 2009, 97, 80-85. [CrossRef]

5. Jiang, T.; Li, G.H.; Fan, X.H. Desilication from diasporic bauxite by roasting-alkali leaching process. Chin. J. Nonferr. Met. 2000, 10, 534-538.

6. Zhu, Z.P.; Jiang, T.; Li, G.H.; Huang, Z.C. Thermodynamics of reaction of alumina during sintering process of high-iron gibbsite-type bauxite. Chin. J. Nonferr. Met. 2009, 19, 2243-2250.

7. Shi, G.S.; Fang, J.; Yang, G.Y.; Xin, H.Y.; Gao, Y.J. Feasibility Study of Guangxi High-Fe Bauxite Sintering. J. Hebei Polytech. Univ. Nat. Sci. Ed. 2013, 33, 11-13.

8. Kahn, H.; Tassinari, M.M.L.; Ratti, G. Characterization of bauxite fines aiming to minimize their iron content. Miner. Eng. 2003, 16, 1313-1315. [CrossRef]

9. Papassiopi, N.; Vaxevanidou, K.; Paspaliaris, I. Effectiveness of iron reducing bacteria for the removal of iron from bauxite ores. Miner. Eng. 2010, 23, 25-31. [CrossRef]

10. Natayauan, K.A. Some microbiological aspects of bauxite mineralization and beneficiation. Miner. Metall. Process. 1997, 14, 47-50.

11. Yeh, C.H.; Zhang, G.Q. Stepwise carbothermal reduction of bauxite ores. Int. J. Miner. Process. 2013, 124, 1-7. [CrossRef]

12. Hu, W.T.; Wang, H.J.; Liu, X.W.; Sun, C.Y. Effect of nonmetallic additives on iron grain grindability. Int. J. Miner. Process. 2014, 130, 108-113. [CrossRef]

13. Hu, W.T.; Wang, H.J.; Liu, X.W.; Sun, C.Y. Correlation between aggregation structure and tailing mineral crystallinity. Int. J. Miner. Metall. Mater. 2014, 21, 845-850. [CrossRef]

14. Hu, W.T.; Wang, H.J.; Liu, X.W.; Sun, C.Y.; Duan, X.Q. Restraining sodium volatilization in the ferric bauxite direct reduction system. Minerals 2016, 6, 31. [CrossRef]

15. Cai, Z.L.; Feng, Y.L.; Li, H.R.; Du, Z.W.; Liu, X.W. Co-recovery of manganese from low-grade pyrolusite and vanadium from stone coal using fluidized roasting coupling technology. Hydrometallurgy 2013, 131-132, 40-45. [CrossRef]

16. Hu, W.T.; Wang, H.J.; Sun, C.Y.; Tong, G.K.; Ji, C.L. Direct reduction-leaching process for high ferric bauxite. J. Univ. Sci. Technol. Beijing 2012, 34, 506-511.

(c) 2017 by the authors; licensee MDPI, Basel, Switzerland. This article is an open access article distributed under the terms and conditions of the Creative Commons Attribution (CC BY) license (http:/ / creativecommons.org/licenses/by/4.0/). 